Kalpa Publications in Engineering
Volume 2, 2018, Pages 67-73
Proceedings on International Conference on Emerg-
ing Trends in Expert Applications \& Security (2018)

\title{
Unlocking the Enigma of e-Governance in Rural Areas in Perspective to State of India
}

\author{
Dr. Avinash Sharma ${ }^{1}$ Nishi Gupta ${ }^{2}$, Dr. Sanjeev Rana ${ }^{3}$ \\ MMU Mullana \\ Sh_avinash@yahoo.com
}

\begin{abstract}
The concept of an e-Governance system came into existence just few years back. Its main objective is to provide access to government services to every individual 24 hours a day as well as 7 days a week. It involves large number of confidential data and information that can be accessed by citizens through media. In nutshell, we can say that online working of a government or providing its services online to its citizens at their door step is known as e-Governance. In today's scenario, growth of any country can be measured by the scope of e-Governance in that country. In this paper, we highlighted various challenges and issues including security issues, different languages issues, geographical areas issues etc being faced by e-Governance system in rural India.
\end{abstract}

Keywords: e-Governance, Security issues, Different Languages

\section{Introduction}

The concept of an e-Governance system is to provide access to government services anywhere, any time. Many definitions for e-Governance in the literature exist. According to [1] "e-Governance is a special application area as an information network. It involves large number of confidential data and information, its role is to enable citizens to access government services any time and any place through media". Another definition by [2] is "e-Governance is use of information technology to provide better and faster online services in addition to information for citizens, businesses and employees by government". It is not difficult for people in developed countries to imagine a situation in which all interaction with government can be done through one counter 24 hours a day, 7 days a week, without waiting in lines. However to achieve this same level of efficiency and flexibility for developing countries is going to be difficult. The benefit of e-Governance for citizens are increasing satisfactions, citizen's convenience and independence, saving their time, effort, and cost. Main pillars of e-Governance can be shown by figure 1.1. 


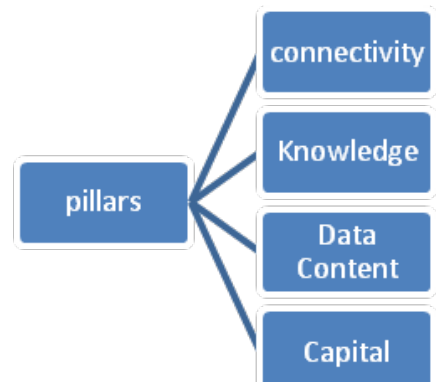

Figure 1.1: Pillars of e-Governance

\section{Information Security in e-Governance}

Trust on e-Governance plays a significant role to increase efficiency and effectiveness on transparent information flow between governments business and citizens. As the number of eGovernance services introduced to the user increases, a higher level of security is required. Information security is a set combining organizational security and IT security. The objective of information security is to preserve an organization's information assets and the business processes they support in the context of (Bell, 2001): Confidentiality ensuring that information is only available to the people and Systems authorized to receive it. Information may be confidential for many reasons including privacy, commercial or political. Integrity ensuring that information is only changed by people and systems Authorized to make changes to it. Availability ensuring that information and information processing systems are available when information is required.

\section{Related Work}

Main objective of e-Governance is to provide security with the internet attacks i.e. protection from unauthorized access, use, disclosure, disruption, modification, perusal, inspection, recording or destruction. We can say that e-Governance security is considered one of the crucial factors for achieving an advanced stage of e-Governance. Since Nepal is an underdeveloped country whose development can be rapid through proper implementation of secure e-Governance system. Authors in [5] proposed a cost effective security framework for e-Governance system for Nepal. They also provided a comparative and suggestive framework for understanding, clarification and investigation of the security issues involved in improving e-Governance security in technologically-underdeveloped countries. Ensuring security of e-Governance applications and infrastructures is crucial to maintain trust among various departments to store, process and exchange information over the e-Governance systems. Due to dynamic and continuous threats on government information security, policy makers need to perform evaluation on existing information security strategy as to deliver trusted and confidence e-Governance services. In [6], authors presented an information security evaluation framework based on fuzzy logic techniques to help policy makers conduct comprehensive assessment of e-Governance security strategy.

ICT plays a key role in e-Governance, and so it becomes essential that ICT reaches rural masses. This will lead to good governance which in turn will lead to better administration, better 
interaction, less corruption and more transparency in the government. [7] Deals with the challenges faced in implementing e-Governance in rural areas of India, various e-Governance projects taken by the government and initiatives that should be taken for successful implementation of E-Governance in rural India. In [8], authors studied about various factors contributing towards the lack of eGovernance service utilization by rural area people. They observed that various projects were implemented mainly at district, tehsil and sub-tehsil level which were far away from the access of rural citizens. To get services, a lot of time and money was wasted by these citizens. Even, most of the time these people were misguided by the agents as they did not knew how to get the services and the actual charges of services. Also, rural citizens were not aware about running projects that is why; they were not able to access the services. Authors in [9] observed that urban areas were in good position in form to avail the services of e-Governance as they had all the required infrastructure but in rural areas the biggest problem was the non-availability of proper infrastructure as well lack of computer aware citizen. So, Cloud Computing can be a future solution to fulfill that needs. The critical problem discussed for the rural areas was non availability of the necessary infrastructure to implement the eGovernance services. They also discussed how to overcome that problems using the applications of Cloud computing. Cloud computing has many advantages such as cost savings, scalability or high availability, which make it interesting for many sectors. In [10], authors introduced a new set of Security Control Principles called e-Governance Security Matrix (EGSM) especially for the Cloud based E-Governance Systems and then proposed a new e-Governance Security Framework (EGSF) which deploys strong cryptographic security protocols during E-Governance transactions.

Punjab Government had implemented a number of projects at district, tehsil and sub-tehsil levels to serve its citizens. But due to some reasons, rural citizens are not aware about these projects and their services. So these projects are suffering from their poor implementation. Authors in [11] described the factors like availability and usage of internet in villages, awareness of rural citizens about e-Governance projects, satisfaction of citizens from these running projects etc.

In [12], authors provided secure information using steganography. The technique was developed to hide the confidential data with the particular image. It was helpful in security of information, precision and transparency among citizens. They also provide the loopholes of other data hiding technique called cryptography. Authors in [13] conducted a research using a forum with personnel from nine government agencies with follow-up interviews with personnel from a further sixteen agencies. The study identified key issues across a broad cross-section of government organizations. These key issues include awareness and active management support, training and appropriate funding. The issues identified were useful to management when implementing IS Security and undertaking Business Continuity Planning over e-Governance within agencies. Main purpose was to determine the key issues that exist with IS Security and BCP processes for whole of government and then rank and rate them accordingly.

Authors in [14] reviewed literature on the benefits, risks and challenges of e-Governance implementation. Interpretive approach using qualitative analysis was adopted. Case study research approach was used with questionnaires and face-to-face interview survey carried out in public service organizations in Nigeria. From the analysis and findings, authors were able to describe the state of eGovernment in developing country - Nigeria and to make recommendations for its successful implementation.

Authors in [15] focused with aim to explore the nature, role and relevance of the Electronic / Digital Governance using ICTs and wireless technologies for agriculture and rural development in the rural regions. They studied the impact of e-Governance on rural development and methods for improving local environmental governance having regard particularly to the range of interests and actors involved in e-Governance. They examined the current status of electronic governance in Jalgaon district in India. They focused on development of the model using ICTs / Wireless technologies for e-Governance of Jalgaon district in Maharashtra state, India. In [16], authors discussed various factors responsible for good governance, e-government initiatives in different states 
of India, and also included some current challenges for managing e-Government projects in India. They also discussed about the current status of e-Governance in India (Eleventh Five Year Plan Achievements) and future prospects of E-Governance in India i.e. the vision and objectives of the Twelfth Five Year Plan (2012-17), its major recommendations and its targets.

\section{Challenges for e-Governance in Rural India}

Mostly rural India is lagging in development, education, health, entertainment services and the general living standard due to lack of Government support in creating ICT and Wireless infrastructure to reach rural masses. e-Governance not only includes electronic interaction and exchange of information between the citizen and government but also exchange of information between the governments (i.e. government to government). The ultimate goal of any government is to provide services to citizen for better and smooth conduct of administrative operations. In fact e-Governance makes government more user-centered. In developing countries like India, where literacy level is very low and even most of the people are living below poverty line, people are not even aware about the benefits of e-Governance activities and people do not use ICT to a much extent, there exist a number of problems to implement E-Governance activities. There are a large number of challenges in the implementation of e-Governance in Rural India [3]. These challenges include:

a) Environmental and Social Challenges

- Different Language: India is a country where people speaking different languages and the rural areas do not know any other language rather than its local language. As e-Governance applications are written in English language Therefore, it becomes a challenge for the government to write eGovernance applications which are to be implemented for the whole nation in more than one language so that these may be acceptable to the users of a particular language.

- Low Literacy: Literacy can be defined as the ability to read and write with understanding in any language. Literacy level of India is very much low which is a major obstacle in implementation of e-Governance projects. Literacy rate in rural areas stand at $67.67 \%$ with rural male literacy rate $77.15 \%$ and rural female literacy rate $57.93 \%$. Whereas literacy rate in urban areas stand at $84.11 \%$ with urban male literacy rate at $88.76 \%$ and urban female literacy at $79.11 \%$ [4].

- Low IT Literacy: Most of the people in India are not aware about the usage of Information Technology. Thus, in India, having low level of IT literacy, an e-Governance project cannot be implemented successfully. This is a major drawback in which the users are not technically literate to use the technology.

- User friendliness of government websites: Users of e-Governance applications are used by nonexpert users who may not be able to use the applications in a right manner. Such users need guidance to find the right way to perform their transactions. Therefore, government websites must be user friendly so that more and more people can use them easily.

- Services are not accessible easily: The concept of e-Governance is claiming for increased efficiency and effectiveness of the government, but these goals will be achieved only if the service will be available to the $100 \%$ of the citizens. So, every service should be accessible by anybody from anywhere and anytime. Therefore, government has to provide internet access through public terminals as a part of their universal access efforts.

- Lack of integrated services: Most of the e-Governance services which are offered by the state or central government are not integrated. Lack of communication between different departments of government may be its major cause. Therefore, the information that resides within one department has no or very little meaning to some other department of the government.

- Lack of awareness in people: Unawareness is a major challenge in the implementation of eGovernance projects. People are unaware about the facilities provided by the government for their 
use. Although, Government has made initiative in certain cases by broadcasting about their projects on radio, TV and putting banners etc. for awareness among the people.

b) Economical Challenges

- Infrastructure \& Running Cost: In developing countries like India, cost is one of the most important obstacles in the path of implementation of e-Governance where major part of the population is living below poverty line. A huge amount of money is involved in implementation, operational and evolutionary maintenance tasks. it is difficult to connect all rural areas through internet and at times it is difficult to lay wires at these places. In remote areas generally till now there is no basic infrastructure available like connectivity and electricity.

- Applications must be transferrable from one platform to another: e-Governance applications must be independent from hardware or software platforms. Therefore, these applications can be used at any platform irrespective of the hardware or software and from one platform to the other platform. These applications may also help on possible reuse by other administrators.

- Maintenance of electronic devices: As the Information Technology changes very fast and it is very difficult for us to update our existing systems very fast. Regulations of different devices and their different characteristics may vary and the system in use must be capable to handle all the emerging needs. Maintenance is a key factor for long living systems in a rapidly changing technical environment.

- Limited financial resources: The Gross Domestic Product (GDP) is one of the measures o national income and a country's economy. GDP is defined as the total market value of all final goods and services produced within the country in a given period of time. GDP of a country is the measure of its financial strength. India has limited financial resources so as to implement and maintain the eGovernment projects properly.

c) Technical Challenges

- Interoperability: Interoperability is the ability of systems and organizations of different qualities to work together. The e-Governance applications must have this characteristic so that the newly developed and existing applications can be implemented together.

- Scale of applications: E- Governance projects have to be designed to scale from the day one. eGovernance is supposed to affect every citizen of the country, so e-Governance applications must have the scale to interface with every citizen.

- Privacy and Security: A critical obstacle in implementing e-Governance is the privacy and security of an individual's personal data that he/she provides to obtain government services. With the implementation of e-government projects, some effective measures must be taken to protect the sensitive personal information of the people. Lack of security standards can limit the development of e-Government projects that contain personal information such as income, medical history etc.

- Scope of applications: The very first step in creating a good application is to define its scope very well and everything else comes later. The applications which are provided by e-Government, their scope must be known in advance for the accurate implementation of e-Governance projects.

- Geographical problems: Corporate networks reside on reliable and controlled networks. Government networks have to go into all areas which are even unfriendly to live. It is, however, costly to wire up all the villages in the country. So, e-Governance systems must have to use the wireless networks like existing cellular networks to reach the applications into remote areas irrespective of the geographical issues.

- Local language: The acceptance of English language in India is very low. The e-Governance applications are written in English. That is why e-Governance projects do not get success. Hence, the e-Governance applications must be written in local language of the people so that they may be able to use and take advantage of these applications. 


\section{Observations made for improvement of e-Governance System}

- The Literacy rate needs to be increased: Literacy is considered an important factor in economic development.. In fact Government has set up many primary schools in various areas. But this has not been successful .So, more emphasis is to be given on the improvement of these schools. Reasons cited for so is lack of proper infrastructure and basic needs in schools like no drinking water, lack of proper toilet facility, teachers absent from school etc. which discourage students from attending school $[17,18]$.

- ICT Development - Twelfth five year plan has proposed "Removing barriers of cost, language and accessibility and provide equitable access to Internet and its benefits to all. Formulate and implement a national digitization plan and a digital information literacy campaign for enabling the common man to use ICT optimally." This move of Government will also help in reducing the digital divide.

- Cloud Computing - Today, cloud computing plays an important role in IT field. Cloud computing is beneficial for all those areas where technological infrastructure is not proper. According to Vikram Kumar Mallavarapu, Vice President - Sales, Public Sector, Cisco India \& SAARC: "Cloud computing can contribute in a variety of ways to deliver citizen services efficiently and enable IT resources to be provided on demand, at scale in a multi-tenant, yet secured environment [19]."

- More projects like Speech-Based AutomatedCommodity Prices Helpline for needs to be developed - All the e-Governance projects initially initiated used English as the medium of communication. But in rural areas where the people are not at all educated and cannot read and write their native language dealing in English is definitely a problem. This is also a cause of failure of many e-Governance projects. A very good initiative has been taken by consortium of seven institutions (IIT-M, IIT-K, IIT-B, IIT-G, IIIT-Hyd, TIFR\& CDAC-Kol) and coordinated by IIT Madras. A speech based automated commodity prices helpline for AGMARKNET has been introduced in six different Indian languages. In this they have developed an automated system from which the farmers can inquire about the latest price of agricultural commodities in their own native language. Thus the farmers are benefitted from this initiative. More such types of initiatives should be started by the Government so that more and more rural population can interactively interact with the e-Governance projects [20].

- Business Process Re-engineering -For good e-Governance reengineering is essential. The processes, procedures need to be restructured so that there is a great leap in the performance of the e-Governance. For this Strategy, Processes, Technology, Organization and Culture the five components of the business need to be changed [21].

- Setting up of more CSCs - For the benefit of villagers more CSCs should be set up, so that they have easy access to the facilities provided.

\section{Conclusion}

As we know that Information Technology is growing rapidly, Indian government needs to increase the literacy rate andmaking many efforts to provide services to rural India through e-Governance. In this paper, various challenges in the field of e-governance were discussed. Also, awareness among people from rural backgrounds about the benefits and secure use of e-Governance activities need to be spread. 


\section{References}

[1] Z. Bo-ping and Z. Yong, "Research on E-Government System Network Security Based on Immune Agent ", IEEE, Guangzhou, pp. 703-706, 2010.

[2] K. A. Shahkooh and A. Abdollahi, "A strategy-based model for e-government planning", IEEE, Guadeloupe City, pp.1-6, 2007.

[3] [20] P. Mittal, A. Kaur, "E-Governance - A challenge for India", International Journal of Advanced Research in Computer Engineering \& Technology, Vol. 2, Issue 3, 2013.

[4] mhrd.gov.in/adult-education.

[5] P. Upadhyaya, S. Shakya and M. Pokharel, "Information Security Framework for E-Government Implementation in Nepal", Journal of Emerging Trends in Computing and Information Sciences, Vol. 3, No. 7, 2012.

[6] P. V. S. S. Gangadhar, S. Pavani and R. N. Behera, "Evaluate E-Government Security Strategy by using Fuzzy Logic Techniques", Global Journal of Computer Science and Technology Interdisciplinary, Vol. 12, Issue 10, Ver. 1.0, 2012.

[7] N. Srivastava, "E-Governance in Rural India", International Journal of Computer Science and Information Technologies, Vol. 6, No. 1, pp. 741-744, 2015.

[8] N. Yadav and V. B. Singh, "E-Governance: Past, Present and Future in India", International Journal of Computer Applications, Vol. 53, No.7, 2012.

[9] R.S. R. Prasad and V. R. Atukuri, "Cloud Computing Technology for Effective E-Governance", International Journal of Computer Science and Information Technologies, Vol. 3, No. 1, pp. 32413244, 2012.

[10] M. Azim and S. K. Naqvi, "A Security Framework for Cloud based E-Governance System", International Journal of Science, Technology \& Management, Vol. 4, No. 2, 2015.

[11] P. Mittal and A. Kaur, "For Implementation of e-Governance in Rural Areas of Punjab", International Journal of Innovative Research in Computer and Communication Engineering, Vol. 1, Issue 6, 2013.

[12] H. V. Desai and A. A. Desai, "Information Security in E-Governance through Steganography", International Journal of Advanced Research in Computer Science and Software Engineering, Vol. 4, Issue 5, 2014.

[13] S. Smith, "Key Factors in E-Government Information System Security", In Proceedings of $18^{\text {th }}$ Bled E-Conference on Integration in Action Bled, Slovenia, June 6 - 8, 2005.

[14] Olusoyi (Richard) and Z. Irani, "E-Government Implementation Benefits, Risks and Barriers in Developing Countries: Evidence from of Nigeria", In Proceedings of $2^{\text {nd }}$ International Conference on Internet, E-Learning \& Education Technologies ( ICIEET) joint with $2^{\text {nd }}$ International Conference on Information Technology, E-Government and Applications ( ICITEA), 2013.

[15] K. Chaudhari, U. Dalal and R. Jha, "E-Governance in Rural India: Need of Broadband Connectivity Using Wireless Technology", Wireless Engineering and Technology, pp. 212-220, 2011.

[16] P. Malik, P. Dhillon and P. Verma, "Challenges and Future Prospects for E-Governance in India", International Journal of Science, Engineering and Technology Research, Vol. 3, Issue 7, 2014.

[17] www.indianonlinepasges.com/population/literacy-rate in india.html .

[18] www.news.bbc.co.uk/2/hi/south_asia/4051353.stm.

[19] http://www.cisco.com/web/IN/about/network/governance.html.

[20] http://agmarknet.nic.in.

[21] "Report on Business Process Re-engineering for e-Governance Projects", Department of Administrative Reforms and Public Grievances Ministry of Personnel, Public Grievances and Pensions, Government of India, 2010. 